\title{
POSTURAL CONTROL ANALYSIS DURING A STANDARDIZED KICK TASK IN SOCCER ATHLETES
}

\author{
ANÁLISE DO CONTROLE POSTURAL DURANTE TAREFA CONTROLADA DO CHUTE \\ EM ATLETAS DEFUTEBOL
}

Original Article

ARTIGO ORIGINAL

Artículo Original

\begin{abstract}
ANÁLISIS DEL CONTROL POSTURAL DURANTE TAREA CONTROLADA DEL TIRO
ENATLETAS DE FÚTBOL
\end{abstract}

\author{
Bruno Mazziotti Oliveira Alves ${ }^{1,2,5}$ \\ (Physiotherapist) \\ Rubens Alexandre da Silva Jr. ${ }^{3,4}$ \\ (Physiotherapist) \\ Luciano Moreira Rosa² \\ (Physiotherapist) \\ Thiago Rosa de Mesquita ${ }^{5}$ \\ (Physiotherapist) \\ Paulo Rui de Oliveira ${ }^{5}$ \\ (Electrical engineer) \\ Ricardo Lima Burigo 5 \\ (Physiotherapist) \\ Cesar Ferreira Amorim 1,2,5 \\ (Electrical engineer)
}

1. Shandong Luneng Taishan Football Club, Jinan, Shandong, China.

2. Sport Club Corinthians Paulista,

Lab Corinthians R9, São Paulo,

SP, Brazil.

3. Universidade do Norte do Paraná

(UNOPAR), Programa de Mestrado

e Doutorado em Ciências da

Reabilitação (UEL), Londrina,

PR, Brazil.

4. Département des Sciences

de la Santé, Programme de

physiothérapie de l'université

McGill offert en extension à I'UQAC,

Saguenay, Québec, Canada.

5. Universidade da Cidade de

São Paulo (UNICID), Programa

de Mestrado e Doutorado em

Fisioterapia, SP, Brazil.

\section{Correspondence:}

César F. Amorin. Universidade da Cidade de São Paulo (UNICID),

Programa de Mestrado e

Doutorado em Fisioterapia. Rua

Cesário Galero, 448/475, Tatuapé,

São Paulo, SP, Brazil. 03071-000.

cesar@emgsystem.com.br

cesar.amorim@unicid.edu.br

\begin{abstract}
Introduction: Postural control is a determining factor for functional performance and motor skills during sports activities. Objective: The objective of this study was to investigate postural control during the controlled soccer ball kicking task through a biomechanical analysis system. Methods: The sample consisted of 11 professional male athletes recruited using convenience sampling, with a mean age of 22 years. The athletes performed twenty-five precision kicks at a target, with the ball in vertical motion released by means of a hand-held device synchronized with the computed biomechanical measurements. Marking of the lower limb segments involved in the kick and the ball were analyzed by accelerometry, while postural control measures were quantified by a force platform in three axes of movement. The support leg was investigated in single leg stance during all tests on the force platform. The main variables of postural control calculated by stabilographic analysis and computed during the 25 kicks were: center of pressure (COP) displacement area, velocity and frequency of COP oscillation in the anteroposterior and mediolateral directions. The mean was used for final analysis to determine the differences in the three phases: pre-kick, kick, and post-kick. Results: The results revealed significant differences $(p<0.01)$ between the three phases, with the kick phase presenting higher values of postural COP oscillations than the other phases. The COP area and oscillation velocity were the variables with greatest sensitivity to changes in the kick phase, obtaining an effect size of $d=14$ and $d=12$, respectively. In clinical terms, the increase in COP values reached $557 \%$ between the pre-kick and kick phases; this difference was reduced to $241 \%$ when compared to post-kick (i.e., difference between kick and post-kick was 316\%). Conclusion. These results have important implications for the perception of postural control responses during soccer ball kicks and consequently, for injury prevention when motor and sensory deficits are diagnosed in soccer players. Level of Evidence III; Study of nonconsecutive patients; without consistently applied reference "gold" standard.
\end{abstract}

Keywords: Postural oscillation; Soccer; Physiotherapy therapy specialty.

\section{RESUMO}

Introdução: O controle posturaléum fator determinante para execução de gestos funcionais e desempenho motor durante as atividades esportivas. Objetivo: O objetivo deste estudo foi de investigar o controle postural durante a tarefa controlada do chute futebolístico por meio de um sistema de análise biomecânica. Métodos: A amostra foi constituída por 11 atletas profissionais do sexo masculino, recrutados por amostragem por conveniência, com média de idade de 22 anos. Os atletas realizaram vinte e cinco chutes de precisão em direção ao alvo, com a bola em movimento vertical lançada por meio de um dispositivo manual sincronizado com as medidas biomecânicas computadas. A marcação dos segmentos de membro inferior envolvidos no chute e a bola foram analisadas por meio da acelerometria, enquanto as medidas de controle postural foram quantificadas por meio de uma plataforma de força em três eixos do movimento. A perna de apoio foi investigada em apoio unipodal durante todos os testes sobre a plataforma de força. As principais variáveis de controle postural calculadas por uma análise estabilográfica e computadas durante os 25 chutes foram área de deslocamento do centro de pressão (COP), velocidade e frequência de oscilação do COP na direção anteroposterior e médio-lateral. A média foi utilizada para análise final para determinar as diferenças nas três fases: pré-chute, chute e pós-chute. Resultados: Os resultados revelaram diferenças significantes $(p<0,01)$ entre as três fases, sendo que a fase do chute apresentou valores maiores de oscilações posturais do COP do que as demais fases. A área e a velocidade de oscilação do COP foram as variáveis com maior sensibilidade às mudanças na fase do chute, obtendo magnitude de efeito em $d=14$ e $d=12$, respectivamente. Clinicamente, o aumento foi de 557\% entre as fases pré-chute e chute; essa diferença foi reduzida para $241 \%$ na comparação com o pós-chute (ou seja, a diferença entre chute e pós-chute foi de 316\%). Conclusões: Esses resultados têm implicações importantes para o reconhecimento das respostas de controle postural durante o chute futebolístico e, consequentemente, para prevenção de lesões quando déficits sensório-motores são diagnosticados em atletas de futebol. Nível de Evidência III; Estudo de pacientes não consecutivos; sem padrão de referência "ouro" aplicado uniformemente. 


\section{RESUMEN}

Introducción. El control postural es un factor determinante para la ejecución de gestos funcionales y desempeño motor durante las actividades deportivas. Objetivo: El objetivo de este estudio fue investigar el control postural durante la tarea controlada del tiro futbolístico por medio de un sistema de análisis biomecánico. Métodos: La muestra fue constituida por 11 atletas profesionales del sexo masculino reclutados por muestreo por conveniencia y con promedio de edad de 22 años. Los atletas realizaron veinticinco disparos de precisión en dirección al objetivo, con la pelota en movimiento vertical lanzada por medio de un dispositivo manual sincronizado con las medidas biomecánicas computadas. La marcación de los segmentos de la extremidad inferior involucrados en el tiro y la pelota fueron analizadas mediante acelerometría, mientras que las medidas de control postural fueron cuantificadas por medio de una plataforma de fuerza en tres ejes del movimiento. La pierna de apoyo fue investigada en apoyo unipodal durante todas las pruebas sobre la plataforma de fuerza. Las principales variables de control postural calculadas por un análisis estabilográfico y computadas durante los 25 disparos fueron área de desplazamiento del centro de presión (COP), velocidad y frecuencia de oscilación del COP en la dirección anteroposteriory medio-lateral. El promedio fue utilizado para análisis final para determinar las diferencias en las tres fases: pre-disparo, disparo, y post-disparo. Resultados: Los resultados revelaron diferencias significativas $(p<0,01)$ entre las tres fases, siendo que la fase del disparo presentó valores mayores de oscilaciones posturales del COP que las demás fases. El área y la velocidad de oscilación del COP fueron las variables con mayor sensibilidad a los cambios en la fase del disparo, obteniendo magnitud de efecto en $d=14 \mathrm{y}$ $d=12$, respectivamente. Clínicamente, el aumento fue del $557 \%$ entre las fases pre-disparo y disparo; esta diferencia se redujo al $241 \%$ en comparación con la fase post-disparo (es decir, la diferencia entre disparo y post-disparo fue de 316\%). Conclusiones: Estos resultados tienen implicaciones importantes para el reconocimiento de las respuestas de control postural durante el tiro futbolístico y consecuentemente, para prevención de lesiones cuando se diagnostica déficit sensorio-motor en atletas de fútbol. Nivel de Evidencia III; Estudio de pacientes no consecutivos; sin patrón de referencia "oro" aplicado uniformemente.

Descriptores: Oscilación postural; Fútbol; Fisioterapia.

\section{INTRODUCTION}

Soccer represents the sport most practiced by the world population, and according to this premise it is easy to understand the great interest in the investigation of intrinsic and/or extrinsic factors that in any way interfere in its practice, be it amateur or professional. ${ }^{1}$ Among the modalities of investigations carried out in soccer, several types that deal with the motor control actions and their mechanical efficiencies are widely found in the literature, especially the kick action, due to the fact that as well as being frequently performed during the game, it is through this technical action that the main objective of executing the goal is most frequently achieved. ${ }^{1,2}$ However, concrete data on biomechanical parameters in soccer are still very deficient in relation to scientific knowledge and clinical practice for injury prevention and, when necessary, athlete recovery. ${ }^{2,3}$

Based on a literature review on the importance of biomechanics in soccer, ${ }^{1}$ evidence exists on the role of lower limb movement for improved kick accuracy. ${ }^{1}$ However, there are other aspects that should be explored in addition to the angular accelerations of the performing limb, such as the postural control of the supporting leg during a controlled task, in pursuit of the best accuracy of the kicking action., ${ }^{3,4}$ This knowledge will also assist rehabilitation professionals in minimizing the risk of injury to athletes. ${ }^{5}$ In fact, this phenomenon comprises studying the system of postural control that is primordial to program and restore a state of balance to the body during an infinity of postures and activities of daily living. ${ }^{6}$

In brief, the postural control system integrates several sensory systems such as the vestibular, visual, and sensorimotor to perform the postural mechanisms necessary to maintain balance. ${ }^{6,7}$ These mechanisms can be characterized by two main postural adjustments, namely: anticipatory (feedforward) and compensatory (feedback). ${ }^{7}$ These two mechanisms are used for the harmony between the action of the central nervous system (CNS) and the musculoskeletal system to deal with internal and/or external disturbances to body segments. ${ }^{8}$ The feedforward mechanism, for example, occurs when the disturbance is caused by the individual's own movements, and in which the adjustments occur to counteract the expected mechanical effects of the disturbance, and thus, maintain postural stability. ${ }^{9}$ The feedback mechanism, however, is triggered when disturbances arise from external and unexpected forces on the body segments..$^{7-9}$ In other words, when the body disturbance is unpredictable, the postural muscles are activated shortly after the moment of the disturbance, with the objective of reestablishing postural stability. 8,10 These compensations and adaptations, known as compensatory postural adjustments, are triggered by sensory feedback signals that help to control the real effects of a disturbance. ${ }^{10}$

In the context of soccer, these mechanisms are present to maintain postural balance during the different actions of the sport as well as promoting high physical performance in the athletes. ${ }^{3,4}$ As already pointed out, the biomechanics of the soccer kick is the most exploited technical action of this sport. The kick, although not the only functional task in football, represents the main and most commonly used task during the game. 'Although some studies have explored the importance of postural (steady state) control for the motor skills of soccer athletes in a general context, ${ }^{3-5}$ few investigations have generalized their results to the specific context of a controlled kick task, in which velocity and height of the projection of the ball should be standardized to minimize biological errors of measurement during posture maintenance. Knowledge on the mechanisms of postural control used by soccer athletes to develop the kick is of paramount importance for injury prevention and rehabilitation. ${ }^{11}$ In this sense, the main focus of the present study was to investigate this phenomenon, through robust and controlled biomechanical measures, in soccer athletes during the principal soccer action, the kick. The objective of this study was to evaluate postural control by means of stabilographic measures from a force platform during the controlled kick task, comparing its phases (pre-kick, during, 
and post-kick) in soccer athletes. The main hypothesis of this work was that the behavior of postural control in unipodal support would differ throughout the phases of the soccer kick during leg balance tests on the force platform; which would have a direct impact on the performance of the athlete and especially on the precision of the movement faced with the proposed sports action.

\section{METHODS}

The present study is characterized as a descriptive experimental research of transversal and diagnostic design to determine the postural control in the phases of the kick. The sample consisted of eleven male soccer professional athletes recruited by convenience from the local sports community. The anthropometric characteristics of the participants were: mean age 22 years (standard deviation: $S D=3$ ), body mass $69 \mathrm{~kg}$ $(\mathrm{SD}=4.5)$, and height $1.73 \mathrm{~m}(\mathrm{SD}=5)$. As inclusion criteria, all participants were required to belong to the group of professional athletes hired and acting in the same team, as well as using as dominant the right lower limb for execution of the kick. Participants should also not present a history of lesions of the musculoskeletal system in the previous two months, in addition to having no prior history of surgery in the lower limbs or spine. The athletes could not present any neurological alterations or any factors that would impede performance in the tests.

In compliance with the resolution of the National Health Council (196/96), all participants were informed in detail about the procedures used and if they agreed to voluntarily participate in the study, they signed the informed consent form. The research project was approved by the local Research Ethics Committee (CEP: 1.023.310).

The study was conducted at Lab Corinthians R9, local: CET Joaquim Grava - Corinthians Paulista. A one and a half hour session was agreed for the evaluation of each athlete.The same investigator performed all tests to avoid measurement errors. All athletes were familiar with the experimental protocol before starting the test.

For the analysis of the balance during the kick, an electromechanical device was designed and developed. This system, associated with constant predetermined distances in the experimental bench (Figure 1A), made it possible to control kinematic variables of the ball in order to carry out the soccer kick task in a controlled way. The system was designed to control the kinetic characteristics of the ball from the beginning of the task to the stage of the kick at which the foot contact with the ball occurs. The developed research system consists of an electromechanical device called the "vertical ball trigger" (namely here as DVB) and was developed by EMG System do Brazil (São José dos Campos, Ltda SP).

For use of the device with the kick action, an experimental bench was developed for the experiment, as illustrated in Figure 1A. To this end, the distance in the anteroposterior direction $(\mathrm{x}$ ) of the target fixation surface in relation to the positioning of the participant on the force platform was determined at $2.70 \mathrm{~m}$, in this way allowing a suitable distance for the strike, as well as allowing the kick to be executed accurately rather than prompting high velocity of the ball. The final " $x$ " distance between the position of the foot contact with the ball and the target fixation surface was $250 \mathrm{~cm}$, as the ball was fired from the DVB, which was fixed $20 \mathrm{~cm}$ in front of the force platform (Figure 1B). Due to the proximity between the target and the position of the participant on the force platform, it was necessary to place a foam shield between the target and the platform, in order to cushion the impact of the ball with the ground, and in this way not allow the ball to return against the subject.

In relation to the target, its vertical position ( $\mathrm{z}$ ) in relation to the ground was determined as $130 \mathrm{~cm}$. This vertical position (z) in relation to the ground was stipulated after experimenting with two subjects to collect pilot data. The pilot experiment consisted of performing a kicking sequence at the distance (x) of $250 \mathrm{~cm}$, with the vertical height (z) of the target in relation to the ground being progressively increased in variations of $10 \mathrm{~cm}$ from the initial point of $100 \mathrm{~cm}$ to the maximum height of $170 \mathrm{~cm}$. Due to the higher hit rate, the vertical position (z) of $130 \mathrm{~cm}$ was determined to be used during the test. The target was a square with $40 \mathrm{~cm}$ sides, with a smaller square, sides $10 \mathrm{~cm}$, inserted in the center (Figure 1A).

The ball used for this system was UMBRO brand, model X-300, new, with a $67 \mathrm{~cm}$ circumference and mass $0.450 \mathrm{~kg}$.To perform the data collection, the ball was calibrated (PENALTY calibrator) on the same day as the tests with a pressure of $7.0 \mathrm{PSI}\left(0.49 \mathrm{Kgf} / \mathrm{cm}^{2}\right)$ according to the manufacturer's instructions.

A device with a triaxial accelerometer was developed, with dimensions $2 \times 1 \times 0.5 \mathrm{~cm}$, a frequency of operation of $50 \mathrm{~Hz}$, sensitivity of $2 \mathrm{mV} / \mathrm{g}$, range of $\pm 2 \mathrm{~g}$ (EMG System do Brazil, Ltda. São José dos Campos). The device was installed in the athlete's footwear to ensure synchronization

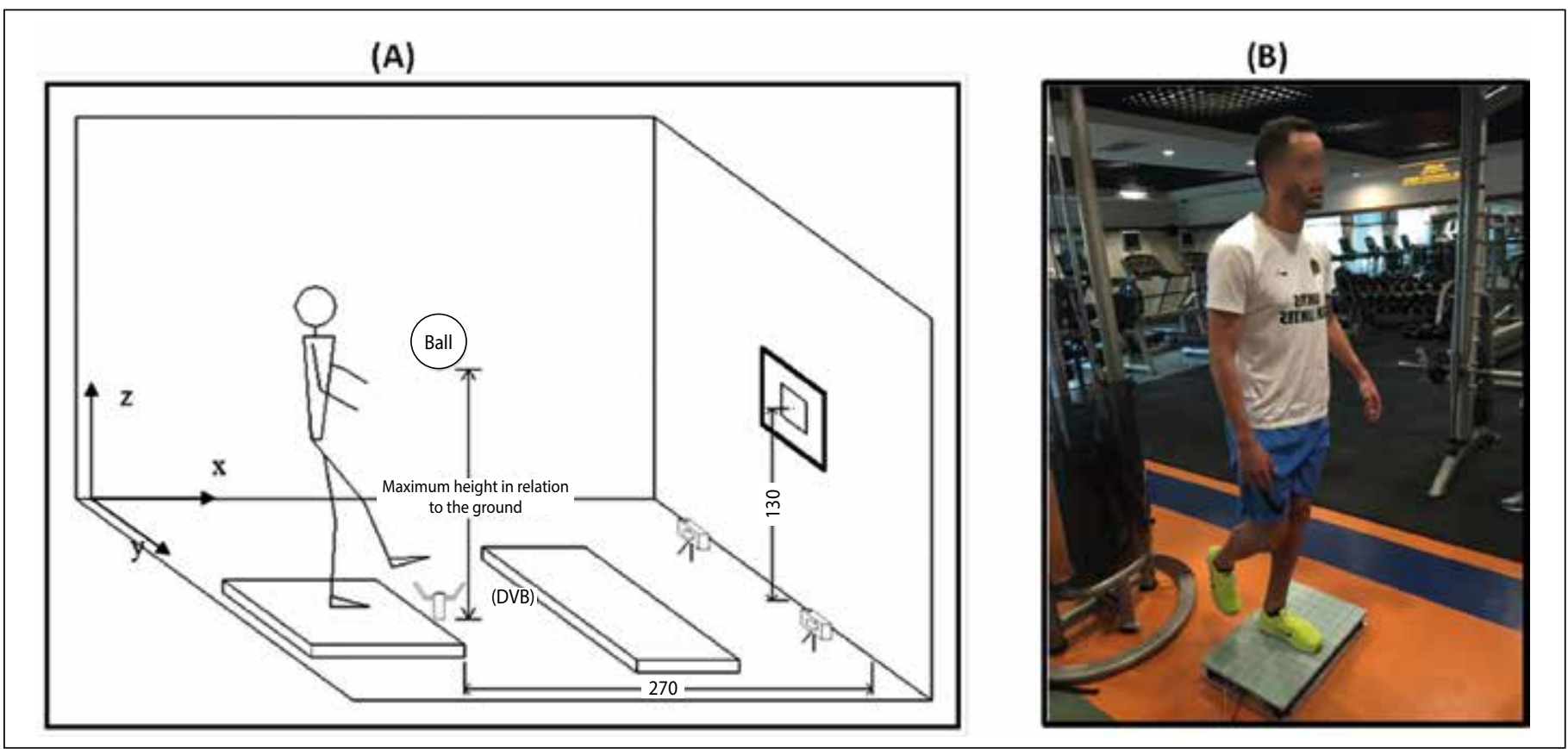

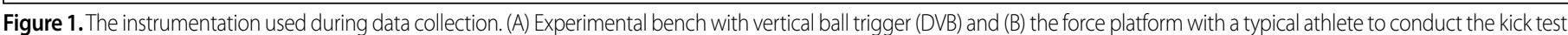


of the moment of impact and intensity of the kick with the other signals involved in the movement connected to the signal acquisition module. ${ }^{4,5}$ The vertical ball trigger, as already mentioned, was carefully instrumented to be triggered automatically by the operator via an electric signal to record the instant of launching the ball. With this procedure it is possible to know how long after release the athlete touched the ball, thus having control of the movement and reaction time during the task. For synchronism of the acquisition of all the signals, a device was developed (trigger) to guarantee that the beginning of the acquisition of the software was simultaneous between the signals of the force platform, device, and accelerometer. ${ }^{4,5}$

To evaluate postural control during the kicking action, the BIOMEC400 force platform (EMG System do Brazil, Ltda São José dos Campos, SP) was used. The force platform measures the vertical force and two of the force moments (or the vertical force and the two coordinates of the center of pressure). ${ }^{12-14}$ These signals are used to calculate the resulting vertical force and its point of application. ${ }^{15,16}$ The force platform consists of a plate under which four load cell type force sensors are mechanically adjusted to measure the vertical forces and respective moments during application of the force $F z$ on it $(x, y$, and $z$ are the directions $A / P, M / L$, and vertical force, respectively) and establish the center of pressure (COP). ${ }^{12-14}$ The COP data refer to a position measure defined by two coordinates on the surface of the platform according to the orientation of the evaluated individual. ${ }^{15}$ The COP data acquired in this study were visualized by a ellipse of COP and a stabilogram. The area ellipse is the map of the COP in the AP direction versus the COP in the ML direction, while the stabilogram is the time series of the COP in each of the directions: AP and ML. (Figure 2) The frequency of acquisition of the signal during the kick was $100 \mathrm{~Hz}$, with the data analyzed by a band pass filter of $0-50 \mathrm{~Hz}$, and a collection duration of 60 seconds. The principal parameters were: anteroposterior position (AP), mediolateral position $(\mathrm{ML})$, anteroposterior velocity (AP), mediolateral velocity $(\mathrm{ML})$, area, AP amplitude and $M L$ amplitude. ${ }^{12-14}$ These parameters have been shown to be sensitive to evaluate the postural control of athletes, especially in the unipodal posture. ${ }^{12-14}$

All the athletes were informed about the procedures that would be adopted to carry out the controlled kick task. The procedures were specifically related to postures and movements that should be adopted before, during, and after the controlled kick task. The task was described for the sample participants and consisted of the following steps: (Figure 1)

a. At a signal from the investigator, climb onto the force platform with the non-dominant foot and remain in unipodal support throughout the period of the controlled kick task;

b. After the ball is released, wait for the vertical movement of the ball to reach maximum height and during the descent of the ball (ground direction) execute the kick, being that the kick should be executed at the most convenient height (ball-ground distance) to hit the target;

c. Make the kick: with the medial region of the foot;

d. The objective of the task is to hit the ball accurately in the center of the target and not with high ball velocity;

e. After contact of the foot with the ball for the execution of the kick, remain in unipodal support with visual focus directed towards the target until the moment at which the researcher signals to descend from the platform with the dominant foot and in sequence with the non-dominant foot that was in contact with the force platform;

f. Controlled kick task completed.

After the instructions regarding the procedures of the controlled task of the kick had been given, each participant was asked to perform kicks using the vertical ball trigger to experience the task for the period required to adapt to the task execution.

The ball was fired manually four seconds after the left foot made contact with the platform. The moment of firing of the ball was registered automatically by the signal acquisition system with synchronization between the equipment (device, platform, and accelerometer). After execution of the kick, the participant remained on the platform in unipodal support, and after the verbal command from the researcher, descended from the platform in reverse, and at no time placed the

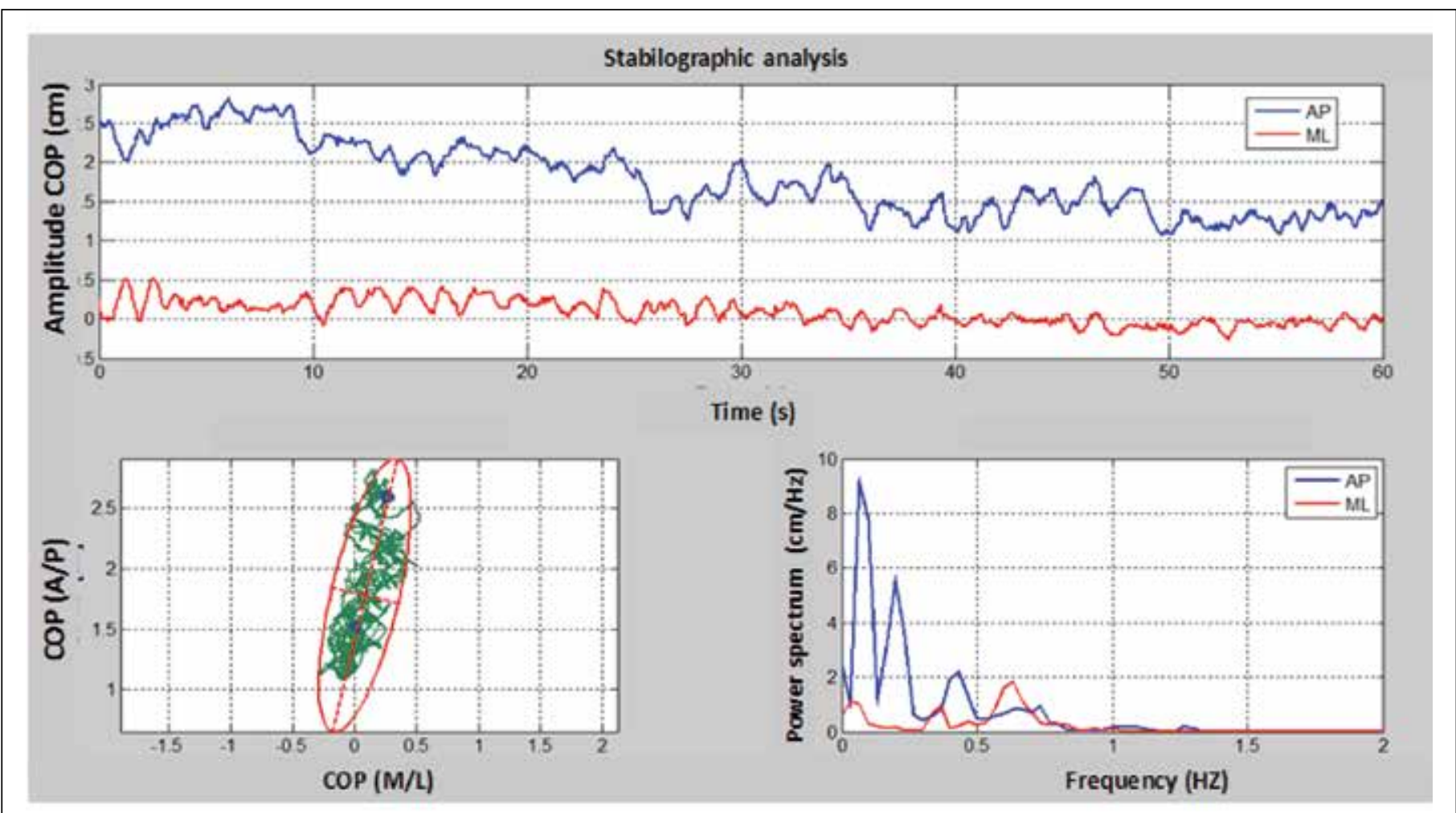

Figure 2. Graphical representation generated by the COP area (ellipse), and stabilogram COP directions (AP and ML), and spectral power density during the kick analysis. 
dominant foot (right) in contact with the force platform. Twenty-five kicks were performed, with a 60-second interval between each kick.

The data were separated into three phases: pre-kick phase, kick phase, and post-kick phase. To determine the instant between the kick phases, two signals were used: a marker coupled to an accelerometer positioned strategically on the foot that performed the kick and the signal of the resulting vertical force coming from the force platform. On average, the effective duration of the kick was 220 to 290 milliseconds. At the same time, on the force platform, a sharp variation in the vertical force caused by the oscillation of the body during the kick was observed on which the stabilographic COP parameters mentioned above were computed. The variations in the accelerometer signals and the vertical force demonstrated synchronism in amplitude and duration, thus allowing the safe use of this time instant to delimit the effective phase of the kick. With this, it was possible to delimit the beginning and end of the pre-kick and post-kick phases. After this step, the collected signals were analyzed simultaneously for each selection of the kick phase of each athlete. The controlled kick task was divided into three phases to facilitate identification of movement control characteristics by means of the COP variation: 1) "Pre" phase: defined from the release of the ball ( $t=$ 0 ) by the DBV to the moment the ball reached the maximum distance (z) from the ground; 2) "Kick" phase: defined from the moment the ball began the descent trajectory in relation to the ground until the moment when the subject made foot contact with the ball; and 3) "Post" phase: defined from the moment when the ball ceased to make contact with the participant's foot. All data were analyzed through the EMGLab and BIOMEC 400 (EMG System do Brazil) programs, which provided data on the three phases defined in the study.

\section{Statistical analysis}

The Shapiro-Wilk test was used to test the normality of the data distribution of the variables from the balance analysis. Initially, a repeated-measures analysis of variance (ANOVA) was used to compare the three kick phases (pre-kick, kick, and post-kick) for all postural balance variables evaluated. The Bonferroni Post hoc was employed to locate the differences between the kicking phases when necessary. The magnitude of the effect size between the kick phases was also computed ( $d$ Effect Size) and classified as: small, medium, and large effect, that is, small $d=0.2, d=0.5$ medium, and $d=0.8$ large, respectively. All analyzes were performed with SPSS version 20 software for Windows and the significance level established for all analyzes was $5 \%$.

\section{RESULTS}

Execution of the controlled kick task was performed successfully, without indications of signs of complexity for the sample participants, with $100 \%$ of the sample completing all twenty-five repetitions of the controlled kick task without difficulties and without adverse signs and/ or symptoms of pain or fatigue. The data of the mean of the variables of postural control during the three phases of the kick are presented in Figures 3 and 4.

In general, the mean of the descriptive data of postural control, through the COP parameters, was elevated when compared to the mean COP data during traditional balance protocols in the literature; denoting the degree of complexity of the motor action investigated. The analysis of variance demonstrated a significant effect $(p<0.05)$ between the kick phases for all balance variables. The post hoc revealed significant differences $(p<0.01)$ between the kick phases in relation to the pre-and post-kick phases (Figures 3 and 4), except for the frequency variable in the $\mathrm{ML}$ direction. (Figure 4)

During the kick, the COP values were highly elevated when compared to the other variables presented in the pre- and post-kick phases; indicating the increase in strategies of postural control to maintain posture during the controlled action. The magnitude of these differences ranged from $d=0.6$ (frequency, Figure 3 ) to $d=14$. (COP area, Figure 4) The variables COP area and COP oscillation velocity presented the greatest sensitivity to the effects of the changes between these kick phases ( $d=14$ and $d=12$, respectively). Clinically, the increase in COP area was $557 \%$ between the pre-kick and kick phase; although this difference reduced to $241 \%$ in the post-kick (i.e., the difference between kick and post- kick was clinically 316\%).

\section{DISCUSSION}

The objective of this study was to evaluate postural control by means of stabilographic measures of a force platform during a controlled kick task in soccer players. Our hypothesis was confirmed. Significant differences were found during the three phases of the kick, in which the kick itself promoted an increase in postural control strategies to maintain posture in comparison to the pre- and post-kick phases. The large size of the magnitude of these differences reached a score of $d=14$ for the COP area variable, with an increase of $557 \%$ in the value calculated compared to the pre-kick phase.

To the authors'knowledge, this is the first study to compare the phases of the kick in a fully controlled experimental scenario, which concerned the projection of the height and velocity of the ball in unipodal support. On the other hand, makes it difficult to compare with other findings in the literature for agreements and disagreements. Several studies have proposed calculating the angular kinematics of the limb in action during kicking, without necessarily observing the strategy of static control of the limb in a unipodal state to increase the precision of the kick in the direction of the target. ${ }^{1-5}$ Therefore, the results of the present study have important implications for knowledge on the sensory-motor mechanisms of the kick action and on the prevention of injuries and rehabilitation of soccer athletes based on motor control.

The majority of findings on postural control in soccer involve pathological populations in their evaluations, which is extremely important. ${ }^{17-19}$ However, it is also fundamental to study a specific condition of an action, such as the kick, to gain knowledge for motor control and injury prevention. ${ }^{20-23}$ Some studies, for example, such as those by the authors Mangus, Wallmann and Ledeord ${ }^{22}$ which analyzed postural control of soccer players after heading the ball, showed no significant difference in balance between pre- and post-header tests. Gualtieri et al. ${ }^{23}$ investigated the correlation between jumping ability in soccer and the ability to control balance. The authors observed a moderate correlation between the tests and concluded on the relevance of balance training to improve jump performance in soccer players. Another analysis of postural control regarding physical fitness was performed by Gstöttner et al., ${ }^{5}$ who compared balance between the preferred and non-preferred limb for kicking in amateur soccer players, and also associated the electromyographic analysis during performance of the tests. The results demonstrated that there is no difference in static and dynamic balance control between the preferred and non-preferred limbs, which supports in part the present finding in investigating only one limb in unipodal support.

In the present study, the variation in mechanisms of postural control for COP area and velocity of oscillation in both directions of movement reached a 557\% increase in stability in relation to the pre-kick control condition. It is worth noting that COP area represents a space by which the center of mass adjustment is made within the support base, while the COP oscillation velocity, which also demonstrated a strong effect $(d=12)$ in its change, represents the ratio of the displacement magnitude of the COP in relation to the time interval required to perform stability 

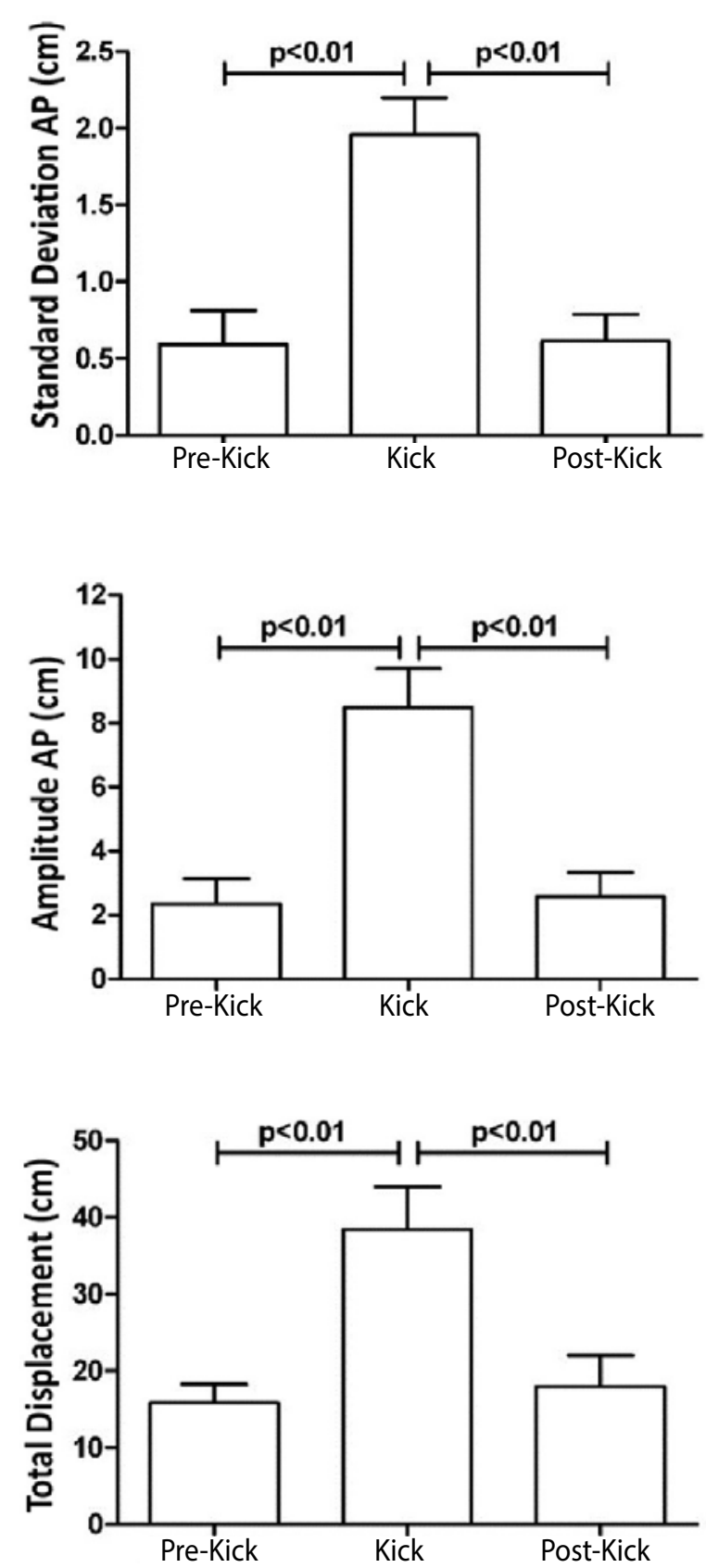
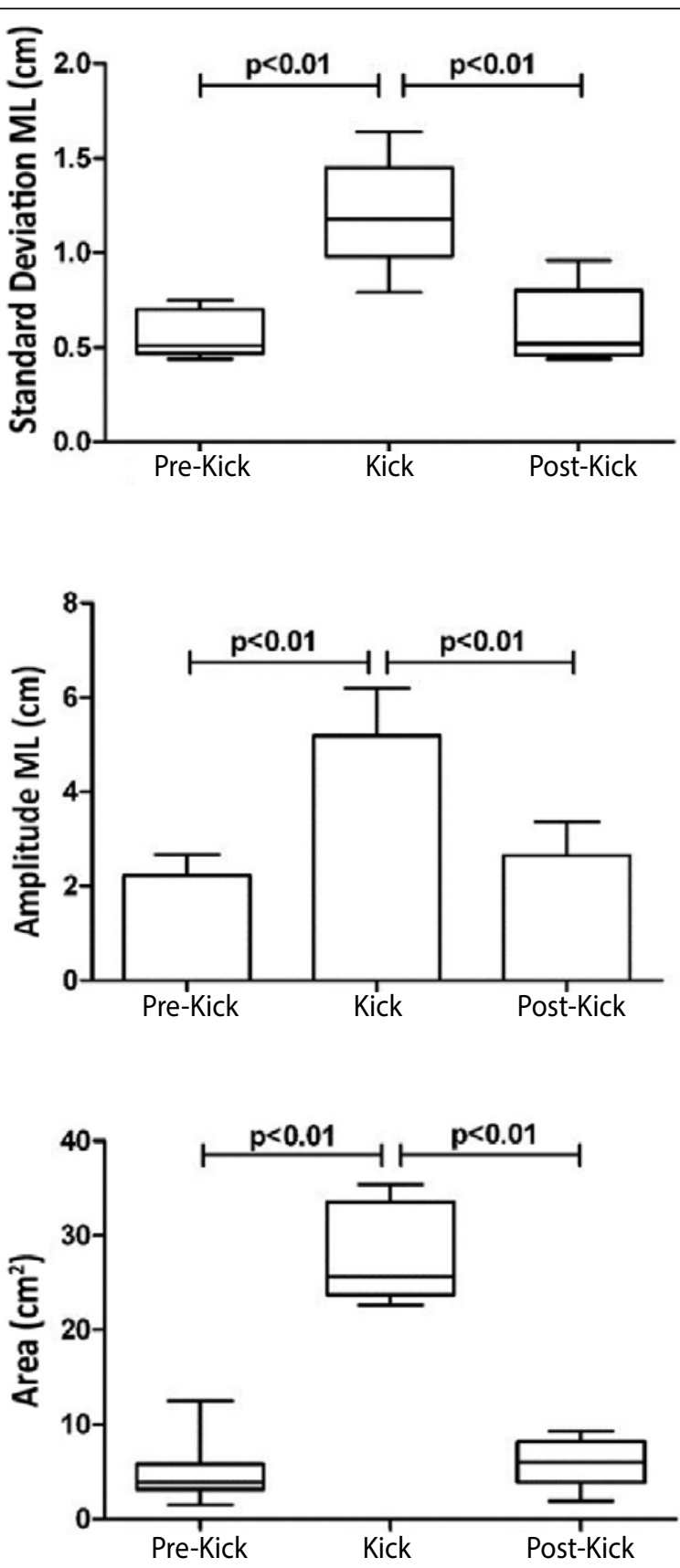

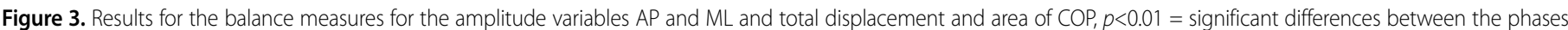
of the kick.

within a small support area. ${ }^{24}$ These two parameters are the most sensitive to predict fall events and are also able to detect sensorimotor deficits in athletes. ${ }^{12-14}$ The unipodal kicking action showed the magnitude of the work of the postural control system in containing the internal and external forces to maintain balance so that the movement itself could be executed with good precision. The postural adjustment mechanisms may become more acute during this action than in the pre- and post-kick phases, as observed in our results. ${ }^{7-10}$

An additional explanation for the findings is the fact that the supporting leg was in unipodal support. ${ }^{25}$ Different studies on postural control have pointed out that this condition is more challenging for the postural adjustment system to maintain balance than other postures in the bipedal condition. ${ }^{12-14,25}$ It is thus expected that the effects of the condition itself promote the increase in the dynamic postural control system to maintain the state of balance during any segmental movement of the lower limbs, faced with the proposed sports action. ${ }^{13}$ As already pointed out, kicking is one of the most prevalent motor skills in soccer and is thus characterized by the need for accurate motor control for accuracy. ${ }^{1,22}$ It is also worth mentioning that in postural control strategies the ankle and hip muscles deal with the corrections necessary to maintain the state of equilibrium of the body when facing postures with small or large challenges. ${ }^{26,27}$ Although these muscles were not evaluated by electromyography in the present study, it is possible that the athletes investigated have significant deficits in muscle clusters around the hip/ trunk in unipodal support. In fact, with the weakness of these muscles, stability becomes more difficult and the postural control system must work more to maintain proper balance, ${ }^{26,27}$ as observed in the results of the present study.

In addition, some previous ${ }^{28}$ and recent works, ${ }^{29}$ demonstrate great muscular activity of the hip muscles, such as the gluteus medius, to 

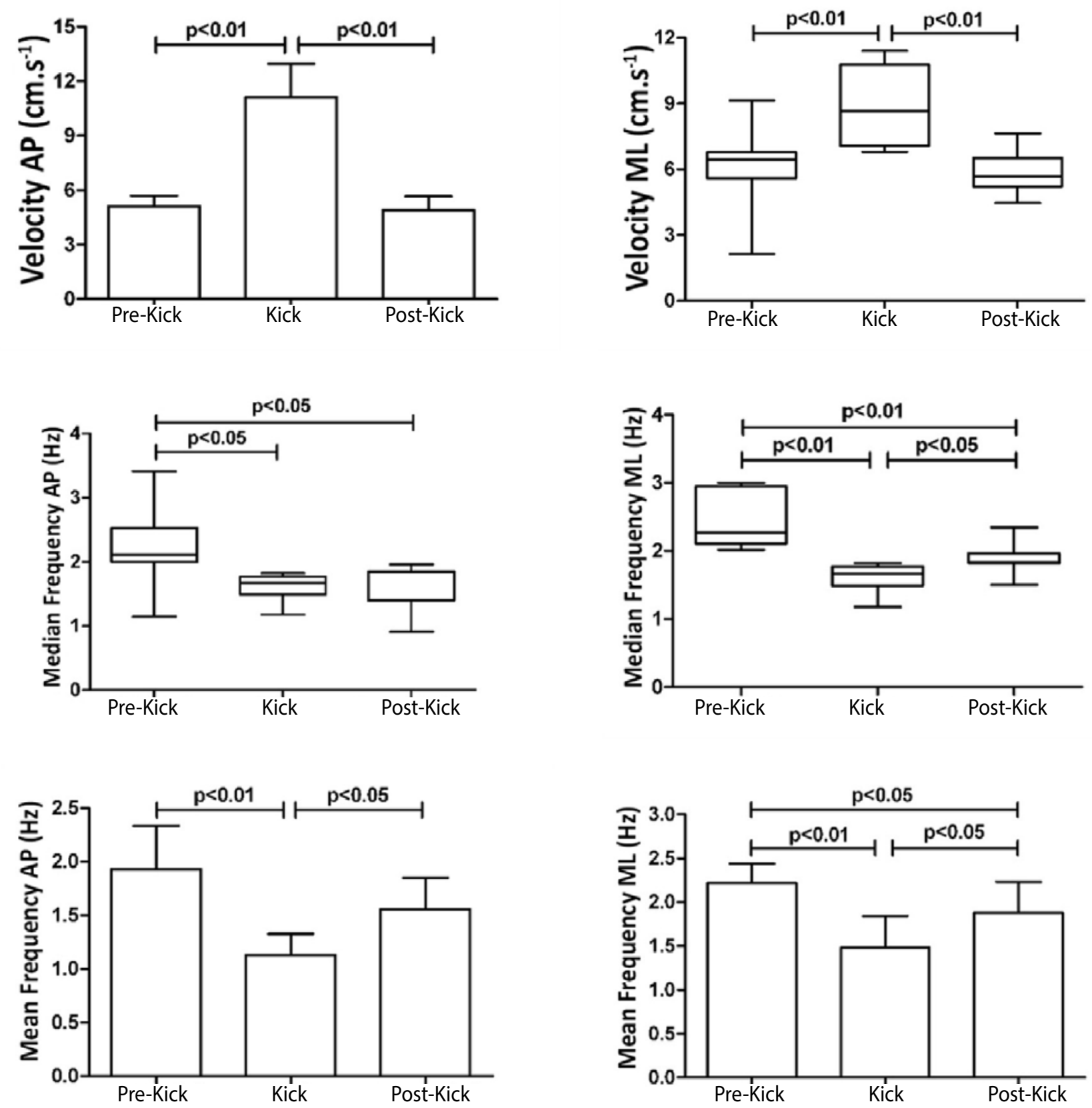

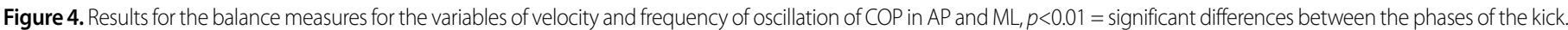

maintain postural balance during unipodal support. The hypothesis for this phenomenon is associated with the mechanical disadvantage of these muscles during unipodal support with the knees in slight flexion. ${ }^{30}$ In this position, a small lever arm of these muscles is observed as well as a shortening of the ischial muscles, ${ }^{30}$ which makes them need to work harder and correct as well as stabilize and control postures. Possible weaknesses of these muscles in athletes also contributes to their greater participation in contrast to the other muscle groupings to maintain the postural stability. ${ }^{31}$

Thus, the present findings demonstrate the importance of implementing motor control training programs in athletes to promote improvement in the performance of muscular groupings involved in postural stability in unipodal support to execute the kick; principally from a clinical perspective of this work where several athletes suffer from neuromuscular injury due to muscle weakness and poor motor control. Gioftsidou et al. ${ }^{32}$ investigated the effectiveness of a balance training program in soccer players, in addition to the effects of post-training fatigue on postural control. These authors observed significant differences in favor of the group that underwent balance training in the parameters of postural control investigated and in the deleterious effects of muscular fatigue; findings that support the hypothesis presented above. Recently, Heleno et al..$^{33}$ supported the use of five weeks of sensorial motor training, performed in a simple and specific way, for functional improvement and, mainly, postural control of soccer athletes; results based on the COP stabilographic data like the variables used in the present study.

Finally, the present study presents some limitations. The lack of evaluation of muscular activity and strength of the athletes through electromyography and dynamometry limited interpretation beyond the findings. Only one unipodal support posture was investigated. The size of the sample does not represent the heterogeneity of all soccer athletes or the sub-classification of game position; this factor may be of importance in future works. 


\section{CONCLUSION}

The present study demonstrated significant differences in postural control during the three phases of the kick, in which the kick itself promoted an increase in the posture strategies to maintain postural balance in comparison to the pre- and post-kick phases. Clinically, a $557 \%$ increase in the calculated value of the COP area was observed compared to the pre-kick phase. These results have important implications for the knowledge on sensory-motor mechanisms of the kick gesture and for the prevention of injuries and rehabilitation of soccer athletes based on motor control.

\section{ACKNOWLEDGEMENTS}

Dr. César F. Amorim was supported by National Counsel of Technological and Scientific Development - CNPq, Brazil (MCTI/CNPQ/ Universal 14/2014- Process: 458880/2014-0).

All authors declare no potential conflict of interest related to this article.

AUTHORS' CONTRIBUTIONS: Each author made significant individual contributions to this manuscript. BMOA (0000-0002-0108-7908)*, RASJ (0000-0001-6879-436X)* and CFA (0000-0003-0137-5659)*: were the main contributors to the writing of the manuscript, concept, analysis and interpretation of results; BMOA (0000-0002-0108-7908)*, LMR (0000-0001-9680-8108)*, TRM (0000-0003-4755-3254)*, PRO (0000-0002-3520-3065)*, and RLB (0000-0001-7358-923X)*: data collection and analysis, manuscript revision and the study's intellectual concept. All authors have reviewed and accepted the final version for publication. ${ }^{*} \mathrm{ORCID}$ (Open Researcher and Contributor ID).

\section{REFERENCES}

1. Lees A, Asai T, Andersen TB, Nunome H, Sterzing T. The biomechanics of kicking in soccer: a review. J Sports Sci. 2010;28(8):805-17.

2. Amadio AC, Serrão JC. Contextualização da biomecânica para a investigação do movimento: fundamentos, métodos e aplicações para análise da técnica esportiva. Ver Bras Ed Fis e Esporte 2007;21:61-85.

3. Dunsky A, Barzilay I, Fox O. Effect of a specialized injury prevention program on static balance dynamic balance and kicking accuracy of young soccer players. World J Orthop. 2017;8(4):317-21.

4. Chew-Bullock TS, Anderson D, Hamel KA, Gorelick ML, Wallace SA, Sidaway B. Kicking performance in relation to balance ability over the support leg. Hum Mov Sci. 2012;31(6):1615-23.

5. Gstöttner M1, Neher A, Scholtz A, Millonig M, Lembert S, Raschner C. Balance ability and muscle response of the preferred and nonpreferred leg in soccer players. Motor Control 2009;13(2):218-31.

6. Pollock AS, Durward BR, Rowe PJ. Paul JP. What is balance? Clin Rehabil. 2000;14:402-6.

7. Godoi D, Barela JA. Mecanismos de ajustes posturais feedback e feedforward em idosos. Rev Bras Ciênc Esporte. 2002;23(3):9-22.

8. Kanekar N, Aruin AS. Aging and balance control in response to external perturbation: role of anticipatory and compensatory postural mechanisms. Age 2014;36:1067-77.

9. Dufossé M, Hugon M, Massion J. Postural forearm changes induced by predictable in time or voluntary triggered unloading in man. Exp Brain Res. 1985;60:330-4

10. Massion J. Movement, posture and equilibrium: interaction and coordination. ProgNeurobiol. 1992;38:35-56

11. Majewski M, Susanne H, Klaus S. Epidemiology of athletic knee injuries: A 10-year study. Knee. 2006;13(3):84-8.

12. Shigaki et al. Comparative analysis of one-foot balance in rhythmic gymnastics athletes. Rev Bras Med Esporte 2013;19(2):104-107.

13. Gil AWiO, Oliveira MR, Rabello LM, Spadão AC, Macedo CG, Pires-Oliveira DAA, et al. Avaliação de diferentes tarefas de equilíbrio em atletas de handebol e futsal feminino. Ter Man. 2012;10(49):148-152.

14. Rabello LM, Macedo CSG, Oliveira MR, Fregueto JH, Camargo MZ, Lopes LD, et al. Relação entre testes funcionais e plataforma de força nas medidas de equilíbrio em atletas. Rev Bras Med Esporte. 2014;20(3):219-22

15. Duarte M, Zatsiorsky VM. Effects of body lean and visual information on the equilibrium maintenance during stance, Exper Brain Res. 2002;146:60-9.

16. Matsuda S, Demura S, Uchiyama M. Centre of pressure sway characteristics during static one-legged stance of athletes from different sports. J Sports Sciences. 2008;26(7):775-9.

17. Gstoettner M, Raschner C, Dirnberger E, Leimser H, KrismerM.Preoperative proprioceptive training in patients with total knee arthroplasty. Knee. 2011;18(4):265-70.
18. Beaupre LA, Lier D, Davies DM, Johnston DB.The effect of a preoperative exercise and education program on functional recovery, health related quality of life, and health service utilization following primary total knee arthroplasty. J Rheumatol. 2004;31(6):1166-73.

19. Cruz-Diaz D, Lomas-Vega R, Osuna-Pérez MC, Contreras FH, Martínez-AmatA.Effects of 6 Weeks of Balance Training on Chronic Ankle Instability in Athletes: A Randomized Controlled Trial. Int J Sports Med. 2015;36(9):754-60.

20. de Noronha M, Refshauge KM, Crosbie J, Kilbreath SL. Relationship Between Functional Ankle Instability and Postural Control. J Orthop Sports Phys Ther. 2008;38(12):782-9.

21. Wikstrom EA, Tillmann MD, Borsa PA. Detection of dynamic stability deficits in subjects with functiona ankle instability. Med Sci Sports Exer. 2005;37(2):169-75

22. Mangus BC, Wallmann HW, Ledeord L. Analysis of postural stability in collegiate soccer players before and after an acute bout of heading multiple soccer balls. Sports Biomech. 2004;3(2):209-20.

23. Gualtieri D, Cattaneo A, Sarcinella R, Cimadoro G, Alberti G. Relationship between balance capacity and jump ability in amateur soccer players of different ages. Sport Sci. Health. 2008;3:73-6.

24. Winter DA. Human balance and posture control during standing and walking. Gait Posture. 1995;3,193-214. 25. Clifford et al. Postural control in healthy individuals. Clin Biomech. 2010:546-51.

26. Gribble PA, Hertel J. Effect of hip and ankle muscle fatigue on unipedal posturalcontrol. J Electromyogr Kinesiol. 2004;14:641-6.

27. Horak FB, NashnerLM. Central programming of postural movements: adaptation to altered support-surface configurations. J. Neurophysiol. 1986;55:1369-81.

28. Harrison EL, Duenkel N, Dunlop R, Russel G.Evaluation of single-legstanding following anterior cruciate ligament surgery and rehabilitation. Phys Ther. 1994; 74(3):245-52

29. Araújo CG, Macedo CSG, Ferreira D,ShigakiL,da Silva RA. Mcconnell's patellar taping does not alter knee and hip muscle activationdifferences during proprioceptive exercises: A randomizedplacebocontrolled trial in women with patellofemoral pain syndrome. J Electromyogr Kinesiol. 2016;31:72-80.

30. Nemeth G, OhlsenH.In vivo moment arm lengths for hip extensor musclesat different angles of hip flexion. J Biomech. 1985;18(2):129-40.

31. Callagahn M, Selfe J, McHenry A, Oldham J. Effects of patellar taping onknee joint proprioception in pacients with patellofemoral pain syndrome. Manual Ther. 2008;13(3):192-9.

32. Gioftsidou A, Malliou P, PPafis G, Beneka A, Godolias G, Maganaris CN. The effects of soccer training and timing of balance training on balance ability. Eur J Appl Physiol. 2006;96:659-64.

33. Heleno LR, da Silva RA, Shigaki L, Araujo CGA, Candido CRC, Okazaki VHA, et al. Five-week sensory motor training program improves functionalperformance and postural control in young male soccer players e Ablind randomized clinical trial. Physical Therapy in Sport. 2016;22:1-7. 